\title{
Comparison of two clinical cases of osteoma and odontoma complex located in the posterior region of the maxilla
}

\author{
Klaudia Zofia Masłowska', Adam Jakimiak', Wojciech Popowski' \\ ${ }^{1}$ Department of Dental Surgery, Medical University, Warsaw, Poland
}

Masłowska KZ, Jakimiak A, Popowski W. Comparison of two clinical cases of osteoma and odontoma complex located in the posterior region of the maxilla. J Pre-Clin Clin Res. 2019; 13(1): 42-49. doi: 10.26444/jpccr/105450

\section{Abstract}

The aim of this paper was comparison of clinical and radiographic images and presentation of treatment methods of two cases of tumours - complex odontoma and osteoma located in the posterior region of the maxilla in two adolescent patients who reported to the Department of Oral Surgery. The first lesion was detected during radiological examination which was ordered due to the absence of the first, second and third molars in the right maxilla on intraoral examination. In the second case, exposure of the bone and absence of teeth in the lateral segment of the left maxilla was noted. On intraoral examination, a fragment of exposed bone, similar in appearance to sequestrum, was visible in the place of missing tooth 27. The tumours in question differed in tissue origin: complex odontoma is a developmental odontogenic lesion, hamartomatic in type, containing haphazardly but clearly defined hard tissue; osteoma is a benign connective tissue tumour originating from bone tissue. In the case of a complex odontoma, the treatment of choice is surgical treatment to perform complete removal of the tumour. A similar approach concerns the osteoma if the tumour deforms the alveolar bone or interferes with proper tooth eruption.

\section{Key words}

osteoma, odontoma complex, bone tumour, $\mathrm{CBCT}$, odontogenesis, impacted teeth, dental surgery

\section{INTRODUCTION}

Odontomas (odontomata) are the largest group (67\%) of tumours of odontogenic origin, developmental malformations, hamartoma. They belong to mixed tumours of odontogenic origin, derived from epithelial and mesenchymal tissues. They are caused by developmental disorders of the dental organ and consist of enamel, dentine, cementum, connective and epithelial tissues. The etiology of these lesions is not fully understood, but predisposing factors for tumourigenesis are pathological conditions such as local trauma or inflammation. The WHO distinguishes two types of odontomas that differ in the structure of tissues inside the tumour and their location: - compound odontoma (OCp, odontoma, compound type; previously complex odontoma, odontoma compositum) $47-74 \%$ tumours of odontogenic origin;

- complex odontoma (OC; odontoma, complex type; odontoma complexum; previously mixed odotoma, odontoma mixtum) - 30\% tumours of odontogenic origin.

Both compound and complex odontomas are slow growing and painless tumours. Due to their asymptomatic growth, they are usually discovered during routine radiographic examination. The most common symptoms of the presence of odontoma are disorders in the eruption of permanent teeth. A tumour that becomes bigger can cause displacement of teeth or distortion of alveolar process of the mandible. Pain, paraesthesia, inflammation around the tumour or resorption of the teeth roots are infrequent occurrences.

\footnotetext{
Address for correspondence: Adam Jakimiak, Department of Dental Surgery Medical University, Warsaw, Poland

Wojciech Popowski, Department of Dental Surgery, Medical University, Warsaw, Poland

E-mail:adam.jakimiak@gmail.com

E-mail: wojtekpop@op.pl
}

Received: 16 November 2018; accepted: 7 March 2019; first published: 21 March 2019
OCp consisting of several formations resembling "small teeth" (odontoids) surrounded by liquids and a connective tissue capsule occurs in the anterior maxilla. Radiographic examination shows a round or oval structure filled with a number of small odontoids, corresponding to the structure of normal teeth, with a radiolucent periphery on the perimeter. This image, together with the results of histopathological examination, allows for diagnosis and choice of treatment. OC is usually located in the posterior area of the mandible, less often in the maxilla and also contains different components of dental structure, but in an abnormal proportion or position. Unlike OCp, the radiological image is not pathognomonic and depends on tumour maturity. In the early stage, complex odontoma is called a soft odontoma, because it creates a round radiolucent lesion with radiopaque periphery, requiring differentiation from an odontogenic cyst. With progressive calcification of the tumour tissues within the lesion there appear poorly radiopaque, irregular shades that in more advanced stage can achieve higher radiopacity than the surrounding teeth. These are the forming streaks of enamel within the dentine-like tissue mass. Because of the non-specific clinical and radiological symptoms, the diagnosis of complex odontoma may be difficult [1]. Many cancers and tumours of odontogenic origin are characterized by a radiographic image, strongly radiopacity, amorphous mass of tissues with a radiolucent periphery and an impacted tooth in the vicinity. Differentiation with complex odontomas is particularly necessary for other tumours of odontogenic origin: ameloblastic fibroodontoma, ameloblastic fibrodentinoma, calcifying cystic odontogenic tumour and rare odontoameloblastoma. AFO is considered as an immature form of complex odontoma [2]. Other tumours of odontogenic origin, such as an adenomatoid odontogenic tumour, Pindborg tumour or cementoblastoma, also focal bone dysplasia, can show similiar radiographic image. 
Odontomas are much more common in permanent dentition, rarely occurring in deciduous dentition. In these individual cases, after surgical removal of the tumour, spontaneous eruption of the deciduous tooth is usually expected. Since impaction of a milk tooth can cause disorders in the development and eruption of permanent teeth, longterm observation is recommended until the milk dentition is fully replaced with permanent dentition [3]. Odontomas are most often diagnosed in children and adolescents, usually in the $1-3$ decade of life, $3 / 4$ cases before the age of 20 . OCp occurs with the same frequency in both genders, OC is slightly more common in males (1.5:1).

Each type of odontoma is treated surgically by complete removal of the tumour. If the tumour is not removed radically in toto, there is a risk of recurrence, especially for OC tumours in the early stages of development. Also, the presence of numerous, small, well-formed odontoids in Ocp, and the possibility of leaving them in the operating area, can make proper eruption of teeth impossible. After removal of the odontoma, radiological examination is recommended to evaluate the completeness of the tumour removal procedure.

In the maxilla and the mandible, the image of focal bone density can also be caused by cancers whose origin is not associated with dental organ. Among them, osteomata, which belong to non-epithelial tumours, should be mentioned. Osteomas are derived from cortical or cancellous bone tissue, and depending on the superiority of one of them, there are durum osteoma (o. eburneum) and osteoma spongiosum. The process of tumour tissue formation is similar to normal ossification and the most frequent locations include: the paranasal sinuses, calvaria, the hard palate in the maxilla, and the inner surface of the body of the mandible. If osteoma is not present in the maxillary sinus, the mandible localization is much more common than in the maxilla. Most commonly, osteoma occur on the body of the mandible and in the area of mandibular angle, but some authors claim that the condyle process is the most common location of this kind of tumour [4], and the dominant symptoms are occlusal imbalance or facial asymmetry. Osteomas create external protuberances (osteoma periostalis, exostosis) on the surface of the bone, or they appear inside the bone and cause distortion in the maxilla or mandible (osteoma centrale, enostosis). As is the case with odontomas, the factors that can lead to the occurrence of osteoma include allergic reaction to infection or trauma. Macroscopically, they are oval or egg-shaped tumours characterized by hard cohesion. They grow slowly, as well-defined tumours with a smooth or lobed surface. Similarly to odontomas, they usually remain asymptomatic, rarely reaching greater dimensions; if they do, they compress the nerves causing neuralgia or paraesthesia.

Microscopically, durum osteomas consist of thick trabeculas and a small amount of bone marrow; spongiosum osteomas contain thinner trabeculas among the richer bone marrow and adipose tissue.

Radiologically, osteomas are oval or round, strongly radiopaque tumours. They are very clearly demarcated from the surrounding tissues, but radiopaque periphery is usually not visible. In rare cases, when the tumour is localized in the alveolar process of the maxilla or the alveolar part of the mandible, it may co-exist with an impacted tooth [5].

In addition to osteoma, osteoblastoma can also be distinguished among benign ossific tumours and is histologically similar to osteoid osteoma. In the maxilla and the mandible it is associated with the roots of the lower molars, and is therefore considered as a cementoblastoma in this localization [6]. Osteoma, osteoid osteoma and cementoblastoma are characterized as bone-forming lesions, because in each one, tumour cells produce osteoid or mature bone [7].

Peripheral osteomas do not usually cause diagnostic problems. Radiological image of central osteoma requires differentiation with complex odontoma and Garré's sclerosing osteomyelitis, eosinophilic granuloma and osteosarcoma [8]. Central osteomas are sometimes located near mandibular molars; in this form, they are often recognized as condensing osteitis or idiopathic osteosclerosis [9]. Treatment consists of radical surgical removal of the tumour. Any part that is left, can lead to recurrence, rare as this may be.

\section{OBJECTIVE}

The aim of this study was comparison of clinical and radiographic images and presentation of treatment methods of two cases of tumours - complex odontoma and osteoma located in the posterior region of the maxilla.

\section{CASE REPORT 1}

A female patient aged 17 years was referred by her GDP to the Department of Oral Surgery at the Medical University in Warsaw, for consultation and possible treatment of a lesion located intraosseously in the right maxilla. The lesion was observed during radiological examination, which was ordered due to absence of the first, second and third molars of the right maxilla on intraoral examination. The patient was generally healthy, was not on any medication and did not report any pain in the area of the facial skeleton. On extraoral examination, everything was normal. On intraoral examination, however, a palpable, painless distention of the alveolar process of the lateral part of maxilla, covered with unchanged mucosa was noted (Fig. 1). On the supplied OPG, the lesion was visible as a well-radiodense, spherical shade, clearly separated from the surrounding bone tissue. Contacting the tumour, a fully impacted tooth 16 was present, located at the apex of the root of the second premolar (Fig. 2).

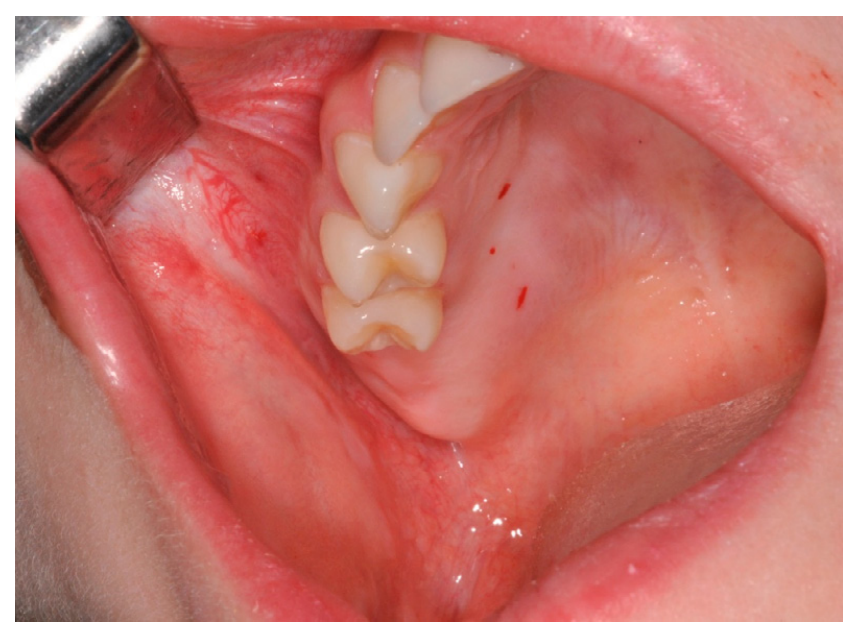

Figure 1. Patient 1. Before surgery. The first and the second upper right molar is missing 


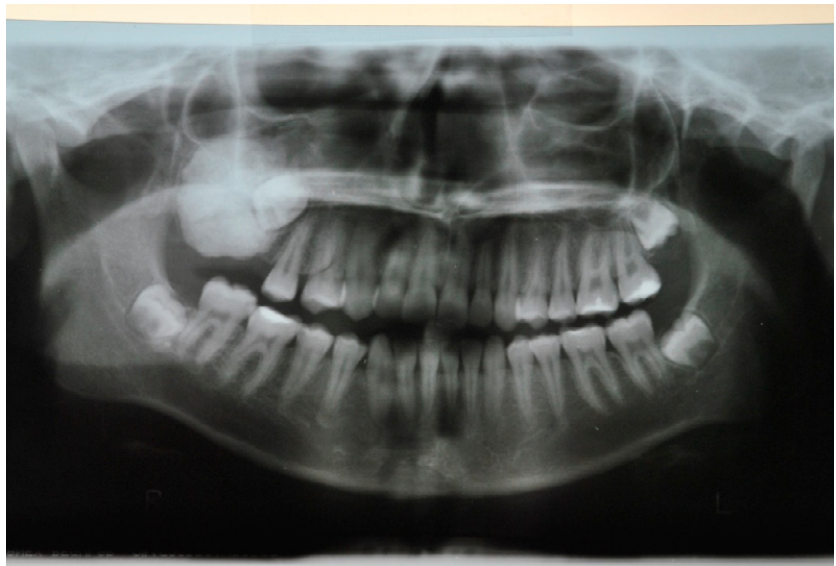

Figure 2. Patient 1. Orthopantomogram

For a more detailed diagnosis, the patient was referred for the CBCT examination of the maxilla. Subsequent scans from examination of teeth 16 and 17 area showed a lesion around $16 \times 18 \times 20 \mathrm{~mm}$ in size and of mixed composition, with dentine and enamel tissue (Fig. 3). Mesially, there was a small osteolitic area and the lesion was surrounded by peripheral osteolysis. On the floor of the right maxillary sinus there was thickening of mucosa to about 7-8 $\mathrm{mm}$. Tooth 16, with finished root development, was impacted in a disto-angled position and its crown surface was in contact with the tumour. Tooth 17 was absent, as was the germ of tooth 18 (Fig. 4). The description of the CBCT scan, location of the lesion, patient's age and radiological image indicated the possibility of a complex odontoma. The tumour located intraosseously was qualified for surgical removal.

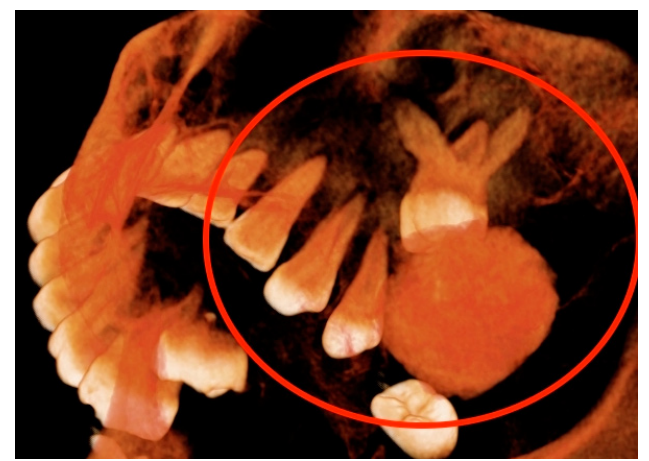

Figure 3. Patient 1. CBCT scan. Osteosclerotic tumour and impacted tooth

After orthodontic consultation, it was decided to attempt to preserve tooth 16 and bring it to the dental arch in a two-stage surgical-orthodontic treatment. Under infiltration anesthesia with $2 \%$ lignocaine with noradrenaline, an incision was made and a trapezoidal mucoperiosteal flap reflected, exposing the surface of the tumour and the impacted tooth 16 (Fig. 5). Next, bone covering the tumour buccally was removed with round burs (Fig. 6). The tumour was removed in toto, tooth 16 was retained, the cavity curetted and rinsed with Metronidazol solution (Fig. 7). The flap was then repositioned and sutures placed. The removed material was submitted for histopathological examination (Fig. 8). Augmentin 0.625 antibiotic was given every 12 hours for 7 days and a follow-up visit was scheduled. Healing after surgery was uneventful, after 7 days the sutures were removed. The result of the

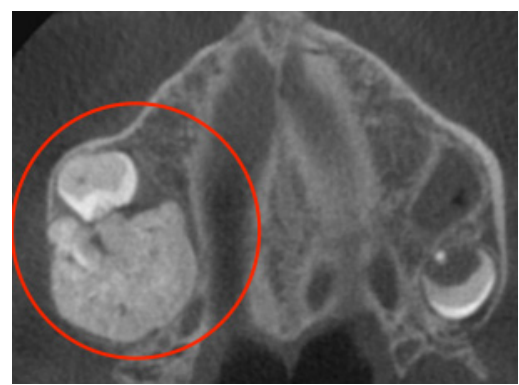

Figure 4. Patient 1. CBCT scan. Osteosclerotic tumour and impacted tooth

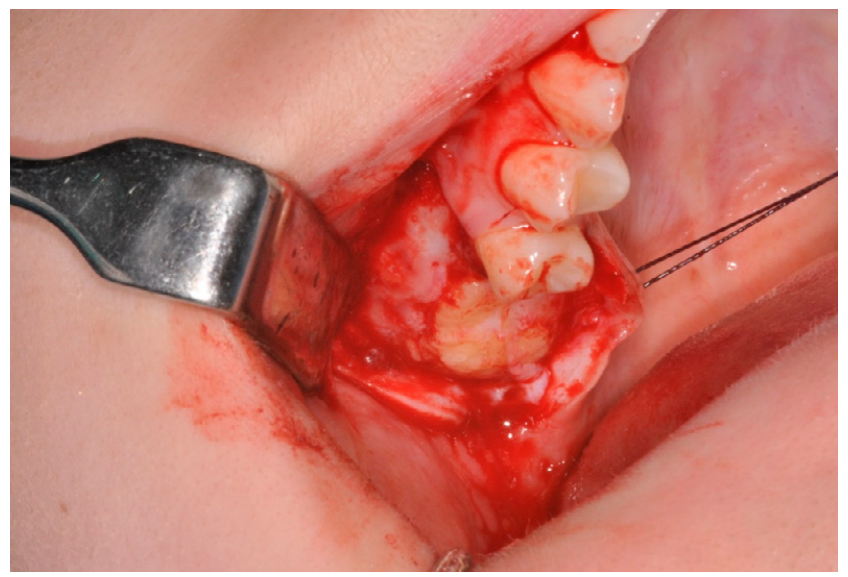

Figure 5. Patient 1. Exposed surface of the tumour after incision

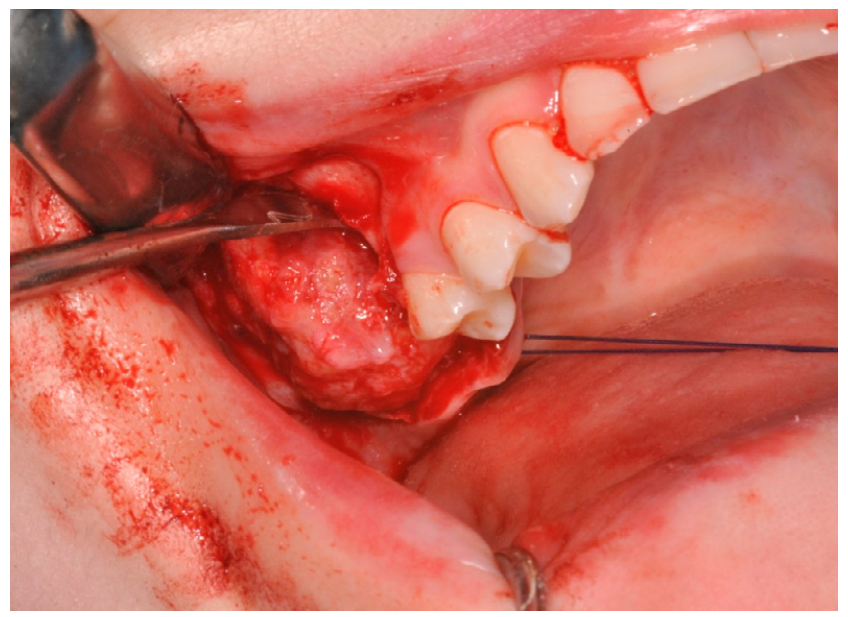

Figure 6. Patient 1. Removal of the tumour

histopathological examination enabled the final diagnosis: a complex odontoma.

After eight months, a CBCT examination was ordered and revealed correct healing of the bone with the formation of spongy bone and formation of compact bone at the operative site (Fig. 9). Tooth 16 slightly changed its position in the bone, its crown projected at a half of the root length of tooth 15 (Fig. 10). No tumour recurrence was observed. Because of the completed development of the root of tooth 16 resulting in its low growth potential, after orthodontic consultation a decision was made to bring the tooth into the dental arch.

At 10 months postoperatively, the second stage of treatment was undertaken. Under infiltration anesthesia with $2 \%$ lignocaine with noradrenaline, an incision was made to reflect a triangular flap in the area of teeth 15-16, exposing the 


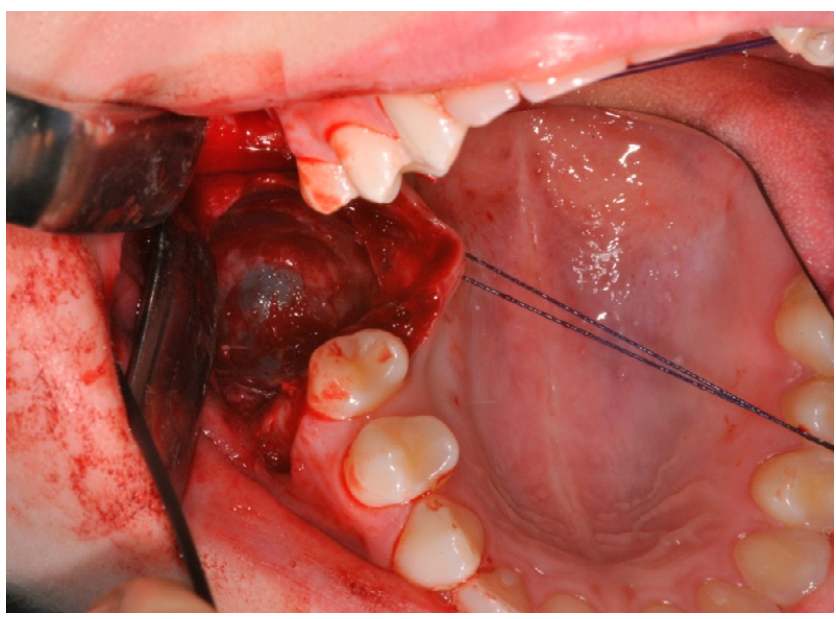

Figure 7. Patient 1. Schneiderian's membrane at the bottom of bone deficiency

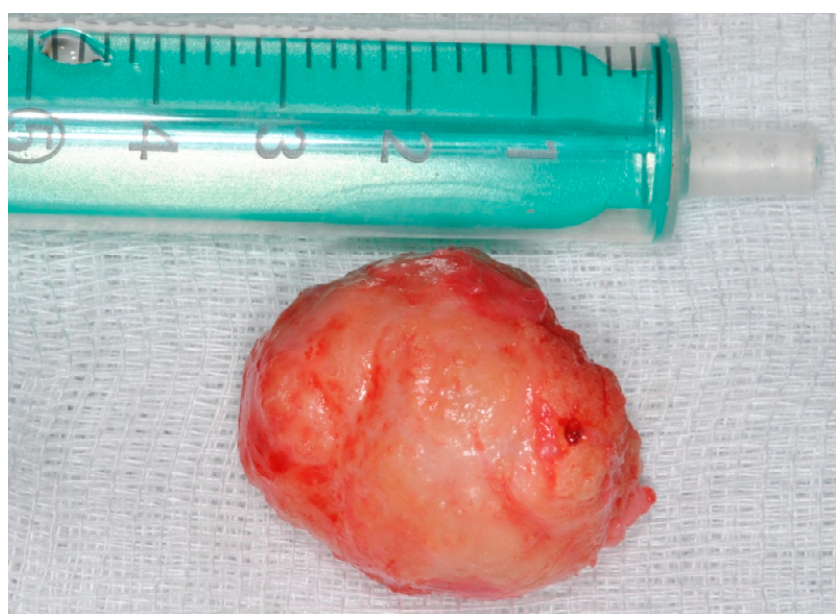

Figure 8. Patient 1. Enucleated tumour

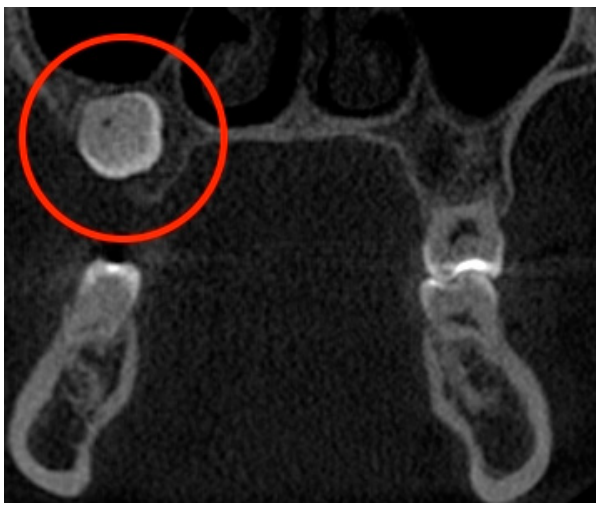

Figure 9. Patient 1. CBCT scan

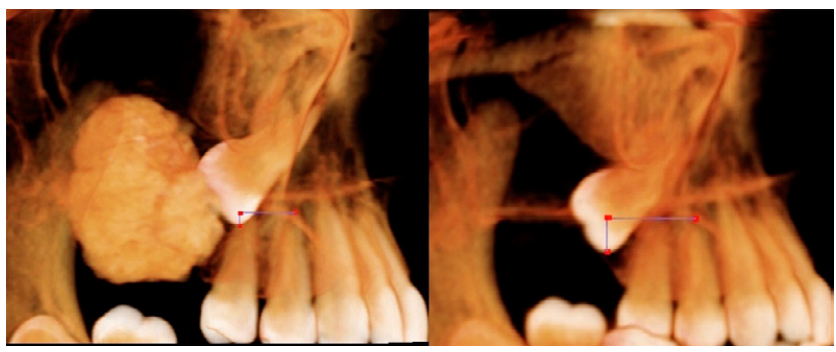

Figure 10. Patient 1. Change in the position of the retained upper right firs molar crown of tooth 16. After etching the enamel, orthodontic brackets with attached elastic ligature were placed. The patient was referred to the Orthodontics Department at the Medical University in Warsaw, where a fixed orthodontic appliance was placed initiating the extrusion of tooth 16. At present, the patient is still receiving orthodontic treatment and remains under constant surgical supervision. Radiological examination and follow-up visits were planned six for and 12 months after the second stage of treatment.

\section{CASE REPORT 2}

A male patient aged 18 years presented at the Department of Oral Surgery at the Medical University in Warsaw following a referral from his GDP because of exposure of the bone and absence of teeth in the lateral segment of the left maxilla. On intraoral examination, a fragment of exposed bone resembling a sequestrum was visible in the place of missing tooth 27.The surrounding soft tissues were not inflamed (Fig. 11). The patient was generally healthy and did not report any complaints within the facial skeleton. As with the first patient, no facial asymmetry was observed extraorally.

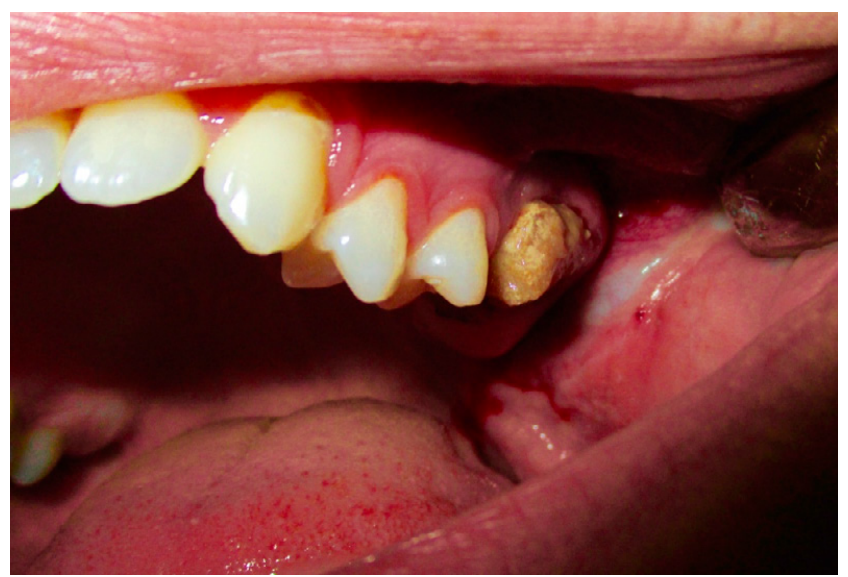

Figure 11. Patient 2. Before surgery. Mass of hard tissue in the place of the upper left first molar

The presence of a mineralized tumour with heterogeneous tissue in contact with the crown of tooth 26 was found in the pantomogram. Tooth 26 was in a disto-angled position above the apex of the root of the second premolar. The germ of tooth 28 was located intraosseously, distally from the radiopaque mass of the tumour, separated by a fine, thin radiolucent periphery (Fig. 12). Surgical removal of the bone tumour with the extraction of tooth 26 was planned.

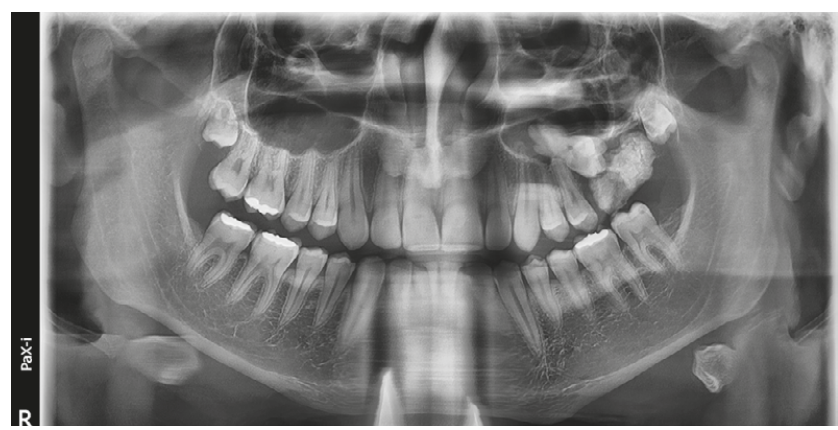

Figure 12. Patient 2. Orthopantomogram 
Under infiltration anesthesia with $2 \%$ lignocaine with noradrenaline, an incision was made to reflect a triangular flap in the area of teeth 25-28 (Fig. 13). The entire bone tumour was removed (Fig. 14), then tooth 26 was removed along with the dental follicle (Fig. 15). A positive result of the Valsalva test was recorded. Plastic surgery of the oroantral fistula was performed and the wound closed with sutures. The removed bone lesion $25 \times 15 \times 10 \mathrm{~mm}$ in size and dental follicle were sent for histopathological examination (Fig. 16). Augmentin 1.0 antibiotic was given every 12 hours for 7 days.

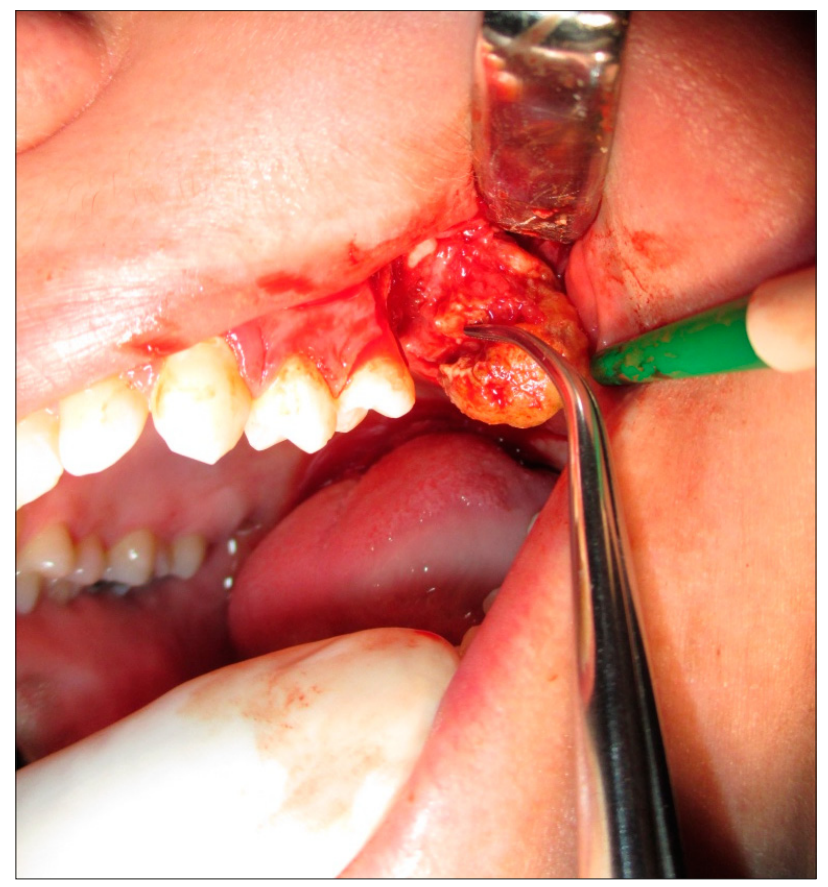

Figure 13. Patient 2. Removal of the tumour

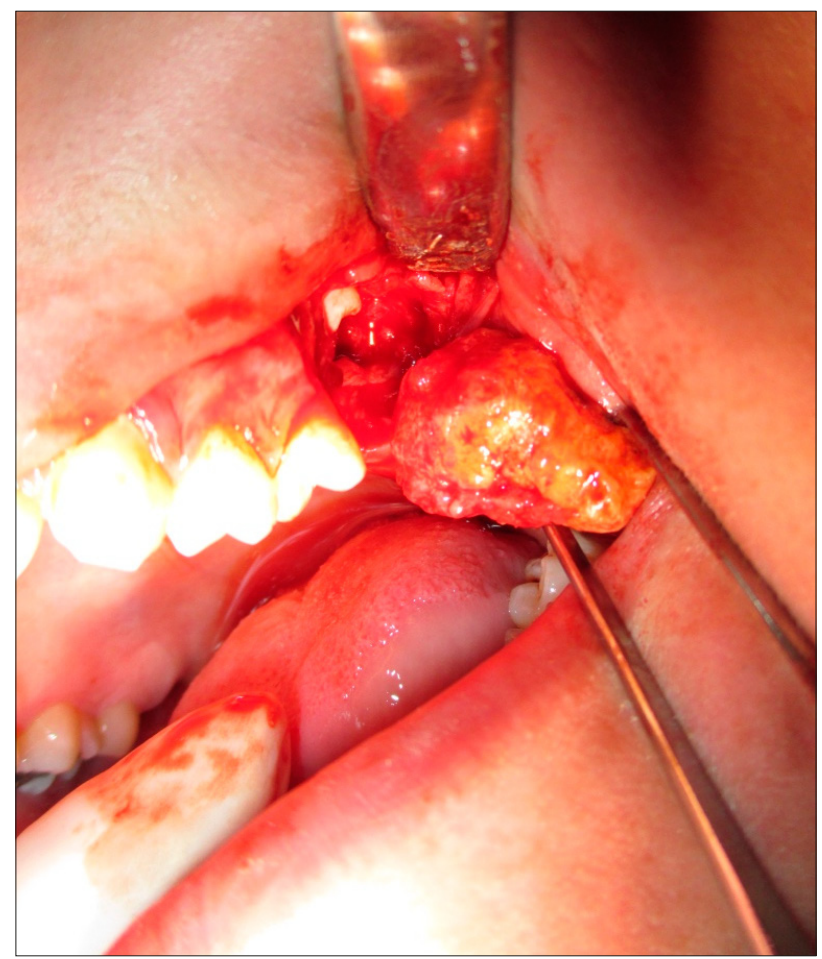

Figure 14. Patient 2. Impacted upper right first molar under the osteosclerotic mass

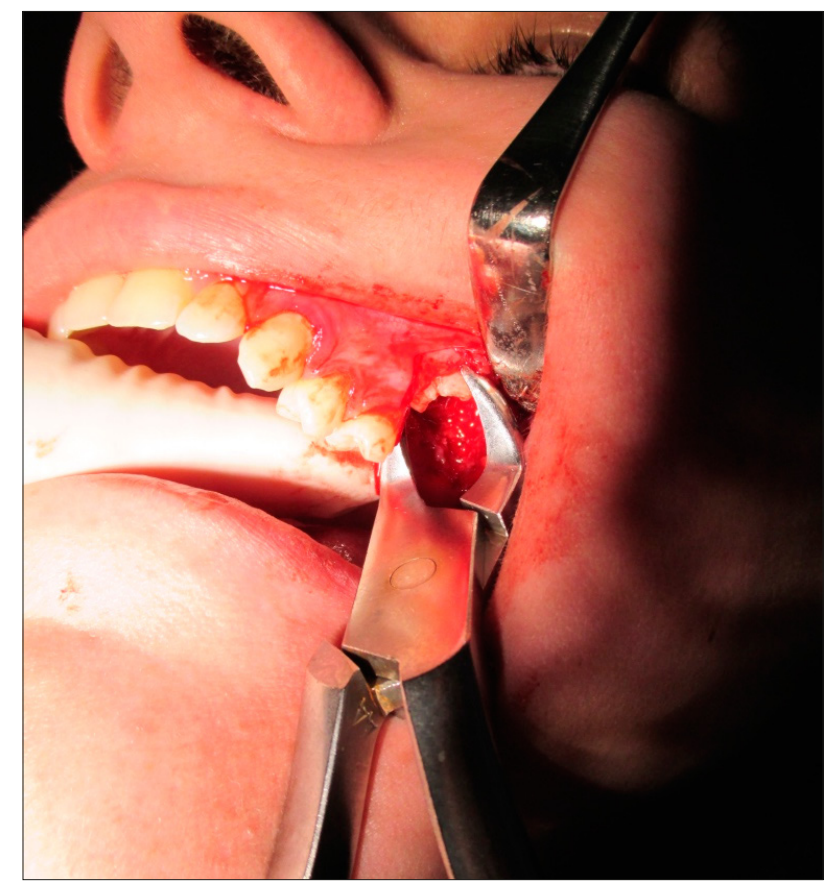

Figure 15. Patient 2. The upper left first molar extraction

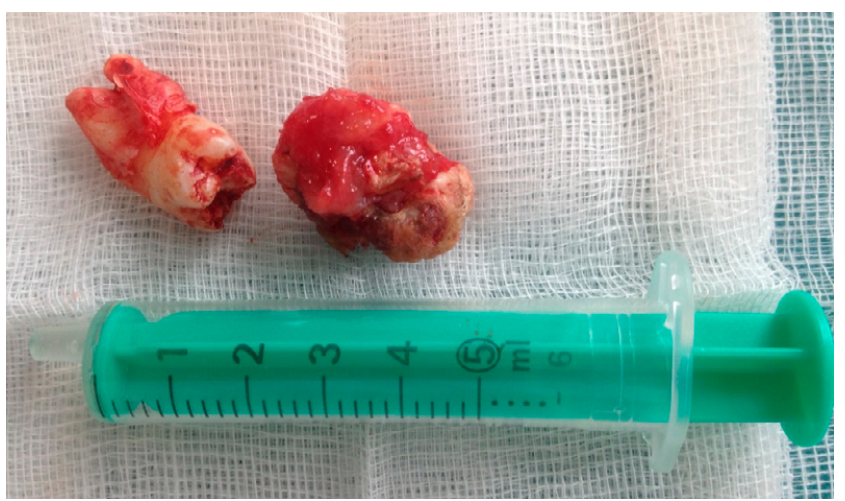

Figure 16. Patient 2. The removed tumour and extracted tooth

At review the next day after the procedure, the patient was in good general condition. A small swelling of the soft tissue of the left cheek was observed and the patient reported minor local pain. After 14 days, the sutures were removed, the wound healed without complications. Histopathological examination result: osteoma.

After 12 months, the patient presented for a follow-up examination. On examination, there was slight loss of the alveolar bone at the operation site. On the CBCT examination, a change in the position of tooth 28 was observed, which may indicate a continuation of the tooth eruption (Fig. 17).

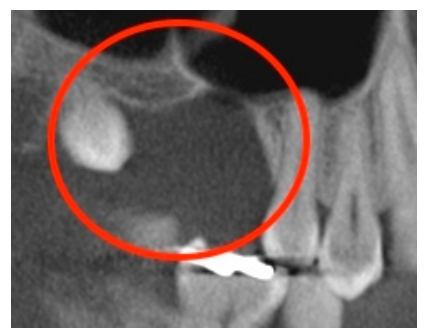

Figure 17. Patient 2. CBCT scan. Sagittal section. Bone regeneration after the procedure 


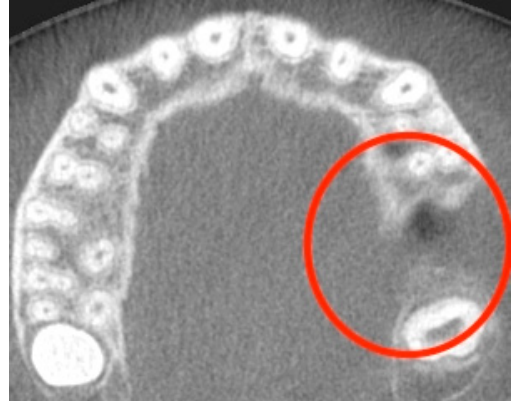

Figure 18. Patient 2. CBCT scan. Axial section. Bone regeneration after the procedure

Healing of bone tissue was normal, on subsequent scans from examination bone reconstruction of normal structure was visible (Fig. 18). The patient was informed of the need for periodic clinical and radiological controls to monitor bone reconstruction and eruption of tooth 28 . Following the eruption of tooth 28 , orthodontic treatment was planned to replace the missing first mandibular molar by mesialization of the third molar tooth, combined with alignment of the patient's occlusal relations. Leaving tooth germ 28 during the enucleation of the tumour and observing the progressing process of its eruption, created the opportunity to reconstruct the dental arch and functional rehabilitation of the patient's stomatognathic system.

\section{DISCUSSION}

In the area of the maxilla and the mandible odontogenic tumours, cancer-like tumours of developmental origin and also benign tumours, not connected with teeth development, can be located. Many of these lesions are characterized by strong, usually heterogeneous radiopacity, oval or round in shape, and a distinct demarcation of the surrounding bone tissue of normal structure and mineralization. The radiological image of a complex odontoma and osteoma, like many other bone lesions, is not typical, and does not allow for differential characteristics. In the area of the facial skeleton, due to the presence of the dental system, there are more lesions of odontogenic etiology whose structures reflect different stages of odontogenesis. Among benign non-dental tumours that deform bone tissue in the facial skeleton, there frequently occur tumours derived from bone and cartilage. Both osteoma and chondroma are also found as primary tumours in the rest of the skeleton, usually in the long bones and in various spinal segments [10].

Most odontomas and osteomas slowly develop in the bones of the jaw and remain asymptomatic for a long time, as confirmed by the cases described. The first symptoms are disorders in eruption of a tooth adjacent to the tumour; distortion of the alveolar bone and pain sensations appear in the advanced stage of tumour development. Both cases of bone lesions presented in this study concerned adolescents between the first and second decade of life. During this period, the dental clinician identifies the disorder at the time or order of teeth eruption. The tooth germ or impacted tooth usually stay in contact with the lesion, but are not fused to the tumour and, as demonstrated in the case of the first patient, its removal is possible without affecting the impacted tooth [11].
Odontomas can develop within forming dental lamina from the cells of external epithelium of the enamel organ, mature ameloblasts or remaining remnants of Serres under the influence of environmental or genetic factors. The strength of the trauma or constant pressure on the forming tooth germ can cause morphological changes leading to odontoma development. The developing tooth germ is replaced by its malformation [12]. The absence of the second and third maxillary molar teeth may suggest that the odontogenic tumour emerged as an abnormality in the tooth germ formation process. It is also possible for an odontoma to form as an accessory, with the correct number of tooth germs [13]. In such a case, the small size of the tumour in the two-dimensional radiological examination is initially diagnosed as an supernumerary tooth.

Osteomas are benign tumours of non-odontogenic origin, and their treatment sometimes requires the removal of the tooth if the tumour causes a significant displacement that makes orthodontic treatment and proper teeth alignment impossible. As stated in the literature, root resorption of the teeth that are in contact with odontomas is possible, but very rare [14]. Also in the case of an osteoma, only individual cases of mandibular molars with partial resorption of root cementum and root dentine caused by neighbouring central osteomas have been described.

Soft tissues surrounding a developing osteoma or odontoma are most often unchanged; in very rare cases the tumour mass may be exposed. In the case of the second patient, at the top of the alveolar process, an exposed calcified tumour fragment, resembling a sequestrum, was found. The porous surface of the exposed hard tissue showed a similarity to the exposed and necrotic inflamed bone. However, the surrounding mucosa did not exhibit inflammatory features, there were no purulent fistulas or exudation from the periodontal pockets of neighbouring teeth. On radiological examination, there were no changes, such as osteoporosis or osteosclerosis in the structure of the surrounding bone, nor were there any features of periostitis, which in young patients often accompanies the inflamed bone. These features enabled the initial exclusion of osteomyelitis. No reports of similar cases of exposed osteoma were found in the literature; only nonskeletal forms of osteoma develop in the tongue or cheek muscles, completely separate from bone tissue [15].

Cases of erupted odontoma have been described and nowadays it is known that these are compound odontomas that have erupted. In the literature, it is suggested that a complex odontoma has a much smaller eruption potential, as demonstrated by the case of the first patient. The mechanism of eruption of odontomas differs from the normal course of teeth eruption [16]. Eruption is due to the eruption forces of the tooth germ; in its absence, bone remodeling or active growth in the connective tissue capsule of the odontoma are implicated. Spontaneous eruptions may be accompanied by pain and swelling that are an exponent of inflammation in adherent soft tissues, and recurrent infections in the erupted odontoma.

In the case of odontomas and osteomas, treatment involves the complete tumour enucleation. On the radiograph, the peripheral radiolucency of the tumour mass is evidence of a thin, fibrous tissue separating the tumour from the surrounding normal bone [17]. In most cases, the separation of a odontoma or osteoma from the surrounding normal bone tissue does not present a challenge. Lack of radiolucency associated with the 
connective tissue around the osteoma may cause the complete separation of these tumours from bone tissue, requiring the use of bone burs or bone chisels [18]. In the case of odontomas and osteomas, management of teeth adjacent to tumours may depend on many factors. Over time, the growth potential of the tooth is finished, which leads to permanent disorders in the eruption of teeth. In the case of teeth with incomplete root development, their spontaneous eruption is possible after removing the obstacle in the form of the tumour. Teeth which are typically impacted due to a developing odontoma are the canines, the central incisors and the third molars. Teeth with the best prognosis for the normal course of eruption following removal of the tumour are those having a halfformed root length. Both cases of impacted teeth with finished root development as well as tooth germs, whose development does not indicate spontaneous eruption, require evaluation of the surgical-orthodontic treatment and extrusion of the tooth into the dental arch. Surgical-orthodontic treatment [23] is undertaken, including the position of the tooth in the bone, extent of its displacement, position relative to the maxillary sinus and neighbouring teeth, and the position of the tooth relative to the tumour. It is necessary to extract the impacted teeth which, despite removal of the obstacle, do not erupt. Orthodontic treatment also provides an opportunity to reconstruct the continuity of the arch by using the teeth adjacent to the tooth missing due to the removal of the impacted tooth. Bringing an impacted tooth into the arch is burdened with a significantly higher risk of failure, especially in the case of deeply impacted molars. Factors such as tooth root development, displacement, rotation of the tooth in the bone, and close contact with the mass of the tumour, make the prognosis of proper tooth eruption uncertain or poor. In such cases, the decision is taken to remove the impacted tooth or the tooth germ, together with the tumour.

Opinions concerning augmentation of bone defects vary. In most cases, sutures are used without the application of grafting materials [19]. Studies show that augmentation procedures significantly extend the potential for implant treatment, especially in the maxilla [20]. Therefore, some authors suggest the use of guided bone regeneration using alloplastic, allogeneic, and resorbable barrier membranes, or autogenous bone grafts to improve bone conditions before planned prosthetic or implant procedures [21, 22]. Performing augmentation immediately after enucleation of an osteoma or odontoma is possible due to the benign nature of these lesions. Despite the rare recurrence after complete removal of the described bone lesions, implantological procedures combined with reconstruction of bone tissue, are carried out in most cases only after several months of observation of the course of the healing process.

\section{CONCLUSIONS}

1) The growth of an osteoma and odontoma in early stages of development is asymptomatic. Symptoms such as slow alveolar process distortion or disorders in teeth eruption are not typical, and can occur in other benign and malignant tumours as well as in bone dysplasia, cysts and even osteomyelitis. Dental disorders in both types of tumours are mostly similar in character, and involve disorders in time and order of teeth eruption, displacement and rotation of the teeth as well as teeth impaction.
2) The radiological image of odontomas and osteomas is not unusual; it is characterized by an oval or round, heterogeneous radiopaque mass, with the distinct demarcation of the surrounding bone tissue of normal structure and mineralization. There is a translucent rim around the odontoma, corresponding to a thin fibrous capsule of the tumour, which is not observed in the case of osteomas.

3) In the case of a complex odontoma, the treatment of choice is surgical treatment to perform complete removal of the tumour. A similar approach concerns osteoma if the tumour deforms the alveolar bone or interferes with proper tooth eruption.

4) Both complex odontoma and osteoma are classified as benign tumours, and the teeth located in the direct vicinity of the tumour should be left in place if there is a chance for their eruption. The early detection of disorders of teeth eruption by a dentist has a significant impact on the course of treatment. Due to the young age of patients, non-invasive treatment is indicated.

5) The inevitable consequence of surgery is significant bone loss deforming the alveolar bone. Consideration should be given to the possibility of bone augmentation for the reconstruction of the alveolar process for future implant treatment.

\section{REFERENCES}

1. Koszowski R, Raczkowska-Siostrzonek A, Morawiec T. Zębiak złożony szczęki - opis przypadku [Odontoma complex - case report]. Mag Stomatol. 2008; 9:34-36. [in Polish]

2. Guilherme Costa Carvalho Silva, Bruno Correia Jham, Edgard Carvalho Silva, Martinho Campolina Rebello Horta, Sebastia o He'lio Pereira Godinho, Ricardo Santiago Gomez: Ameloblastic fibro-odontoma. Case report. Oral Oncology EXTRA 2006; 42: 217-220.

3. Jung-Woo Kim, Teo-Jeon Shin, Hong-Keun Hyun, Young-Jae Kim, Jung-Wook Kim, Ki-Taeg Jang, Chong-Chul Kim, Sang-Hoon Lee. Impaction of primary teeth associated with odontoma: case report. J Korean Acad Pediatr Dent. 2012, 39(1): 36-42.

4. Fernando Kendi Horikawa, Ronaldo Rodrigues de Freitas, Fernando Alves Maciel, Antonio José Gonçalves. Peripheral osteoma of the maxillofacial region: a study of 10 cases. Braz J Otorhinolaryngol 2012; 78(5): 38-43.

5. Janas A, Grzesiak-Janas G. Kostniaki śródkostne w materiale własnym. [Intrabony osteomas in own material] Dent Med Probl. 2005; 42(3): 431-435. [in Polish]

6. Chrysomali E, Schoinohoriti O, Theologie-Lygidakis N, Goutzanis L, Ioannis I. Osteoblastoma of the mandible: a case report with immunohistochemical evaluation. Open J Stom. 2011; 1: 207-211.

7. Greenspan A. Benign bone-forming lesions: osteoma, osteoid osteoma and osteoblastoma. Clinical, imaging, pathologic and differential considerations. Skeletal Radiol. 1993; (22): 485-500.

8. Satish Karandikar, Gagan Thakur, Manisha Tijare, Shreenivas K, Kavita Agrawal. Osteoid osteoma of mandible BMJ Case Reports 2011; 10.1136/ bcr.10.2011.4886, Published XXX.

9. Bulut E, Ozan B, Günhan O. Central Osteoma associated with root resorption. J Craniofac Surg. 2010 Mar; 21, 2, 419-421.

10. Jankowski R, Szymaś J, Nowak S, Żukiel R, Sokół B. Pierwotne nowotwory kostne kręgosłupa [Spine primary bone tumours]. Neuroskop. 2009, 11: 89-103. [in Polish]

11. Heloisa de Oliveira B, Campos V, Marcal S. Compoud odontoma diagnosis and treatment: three case reports. American Academy of Pediatric Dentistry 2001; 23(2): 151-157.

12. Sujatha Govindrajan J, Muruganandhan Shaik Shamsudeen, Nalin Kumar, M Ramasamy, Srinivasa Prasad. Complex Composite Odontoma with Characteristic Histology, Case Reports in Dentistry. Article ID 157614, 5 pages, 2013. doi: 10.1155/2013/157614

13. Rahnama M, Izdebski P, Jedna D. Zębiak złożony jako przyczyna zatrzymania zębów trzonowych w żuchwie - opis przypadku [Odontoma complex as a cause of molar impaction in mandible]. Art Dent. 2015; 4: 248-250. [in Polish] 
14. Ghassen Krichen, Hajer Hentati, Rim Hadhri, Abdelfatah Zakhama, Jamil Selmi. Odontoma associated with supranumerary and impacted teeth. International Dental Journal of student's research. Feb 2013-May 2013; 1(4): 47-51.

15. Mayra L Mesa, Lawrence C Schneider, Leo Northington. Osteoma of the buccal mucosa. Journal of Oral and Maxillofacial Surgery 1982; 40(10): 684-686.

16. Sonika Verma, A Sri Kennath J, Arul, A Sri Sennath J. Arul, 1 and S. Chitra: Erupted complex odontoma of the posterior maxilla: A rarity. Journal of Natural Science, Biology and Medicine 2016; 6: 167-169.

17. Talita Ribeiro Tenório de França, Luiz Alcino Monteiro Gueiros, Jurema Freire Lisboa de Castro, Ivson Catunda, Jair Carneiro Leão, Danyel Elias da Cruz Perez. Solitary peripheral osteomas in the jaws. Imaging Science in Dentistry 2012; 42: 99-103.

18. Emel Bulut, Aydan Acikgoz, Bora Ozan, Omer Gunhan: Large Peripheral Osteoma of the Mandible: A Case Report. International Journel of Dentistry 2010; Article ID 834761, 5 pages, doi: 10.1155/2010/834761

19. Lewandowski B, Cubera T. Zębiaki. Obserwacje własne. [Odontomas. Own observations] Przegląd Medyczny Uniwerytetu Rzeszowskiego Narodowego Instytutu Leków w Warszawie 2010; 3: 323-329. [in Polish]
20. Tuczyńska A, Bartosik D, Abu-Fillat Y, Sołtysik A, MatthewsBrzozowska T. Compoud odontoma in the manible - case study and literature review. Developmental Period Medicine, 2015; 19: 484-489.

21. Szycik V, Dijakiewicz M. Procedury chirurgiczne przy wprowadzaniu implantów ITI Straumann w odniesieniu do warunków anatomicznych w miejscu implantacji. Doświadczenia własne [Surgical procedures during ITI Straumann implant insertion in accordance to anatomical factors in place of implantation]. Ann Acad Med Gedan. 2004; 34: 293-307. [in Polish]

22. Kiewlicz W, Gawrońska-Skorkowska J, Szycik V, Dijakiewicz M. Leczenie implantoprotetyczne po usunięciu zębiaka złożonego żuchwy - opis przypadku [Implantoprosthetic treatment after removal of odontoma complex located in mandible - case report]. Prot Stom. 2005; 60: 357-361. [in Polish]

23. Kozakiewicz M. Kostniaki żuchwy - leczenie z zastosowaniem materiałów kościozastępczych i sterowanej regeneracji tkanek [Mandible osteomas - biomaterials and guided tissue regeneration treatment]. Czas. Stomat. 2001; 1: 57-65. [in Polish] 